\title{
Operating Results of a 20MW Biomass Generating Plant in Italy and a GIS Analysis for Exploiting Wood Availability
}

\author{
A. Cavallo, B. Covili Faggioli, P. Guizzetti, P. Lazzeroni, F. Moretti, F. Stirano, and M. Tartaglia
}

\begin{abstract}
An electric 20 MW generating plant has been installed in northern Italy (Lombardy region) since 2010. Due to connection rules the plant is connected to the national transmission system at $132 \mathrm{kV}$. The biomass chosen as a fuel of the generating plant is mainly poplar chip which is produced in different areas at a distance less than $70 \mathrm{~km}$ in order to limit their environmental impact because of transportation and related emissions and to benefits of the Italian incentives schemes related to the so called "short supply chain".

The paper will illustrate the basic idea and the most significant elements of the plant; its operative results obtained in the last 4 years are also discussed together to the plant emissions.

A particular attention is spent to analyze the biomass composition and cost which make the plant operating life sustainable by the environment and economic point of view. According to the design stage, the electric energy produced by the plant is kept as near as possible to its rated value so that a suitable policy of biomass acquisition, storage and maintenance must be applied.

A suitable GIS tool has also been used to compare the biomass use of the plant and a possible management of Lombardy region in order to better maintain the wooded area within a stated extension $(70 \mathrm{~km}$ maximum distance from the plant).
\end{abstract}

Index Terms - Biomass generation plant, biomass availability by GIS analysis, Italian case study, sustainable short supply chain.

\section{INTRODUCTION}

Energy production is one of the most important future challenges for human societies. In fact, energy production of conventional power plants fueled by fossil fuel has significantly increased the pollution level in Europe as well as in the rest of the world. The increase of renewable and local energy sources can lead a reduction in greenhouse gas (GHG) emissions in European Union (EU) Member States [1] and bioenergy systems can contribute to climate change mitigation if they replace traditional fossil fuel use and if bioenergy production emissions are kept low [2]. For this reason, energy production of renewable energy sources (RES) is playing an essential role in European strategies [3].

The interest into renewable energy sources in Europe has grown in recent decades and a specific focus on forest

Manuscript received April 9, 2018; revised July 10, 2018.

P. Lazzeroni, F. Moretti, and F. Stirano are with the Istituto Superiore Sui Sistemi territoriali per l'Innovazione - SiTI, Torino, Italy (e-mail: paolo.lazzeroni@polito.it).

A. Cavallo, B. Colivi Faggioli and P. Guizzetti are with the Maire-Tecnimont Group, Milano, Italy (e-mail: p.guizzetti@tecnimont.it).

M. Tartaglia is with the Politecnico di Torino - Energy Department “Galileo Ferraris”, Torino, Italy (e-mail: michele.tartaglia@polito.it). biomass usage for energy purpose has been recently highlighted in the energy policy of EU [4]. Forest ecosystems are recognized as important elements of the global carbon cycle as well as the cycle of other greenhouse gases (GHG) that are believed to considerably affect climate [5]. Furthermore, to preserve natural resources for future generations, forest biomass harvests must be conducted in a sustainable forest management framework [6].

According to the European context, this paper intends to present the main results from the energy and environmental point of view of an existing biomass power plant located in the northern part of Italy. The results will highlight that the pollutant emission of the biomass plant can be effectively kept lower than the national and the regional standard limits thanks to the available technology installed in the plant. Moreover, some details about economic benefits for the area close to the power plant will be briefly discussed and presented.

Particular attention will be given to the incentive scheme presently available for biomass plant with a "short supply chain" in the Italian context [7]. This benefit can in fact support the economic sustainability of the plant when the wood chips or raw materials derives from an area within of $70 \mathrm{~km}$ of radius far from the plant location. So, as discussed in the literature [8], [9], a Geographical Information System (GIS) analysis is performed to investigate the potential biomass available from the "short supply chain" point of view. The results are compared to the present biomass usage to verify possible compliancy with the present management.

\section{Biolevano Power Plant}

\section{A. Plant Layout and Energy/Emissions Performances}

The power plant presented in this paper (see Fig. 1) is located in the northern part of Italy. The initiative for installing a power plant based on renewable sources was born in 2005 to take advantage of the opportunities arising from the development of fast-growing biomass energy (Short Rotation Forestry - SRF) chain incentivized by the Lombardy Region's specific plan. After the formal authorization process and the commissioning, the commercial operation of the plant and its electricity generation starts on September 2012 with an installed capacity of 20MW.

The plant operation is based on a mixture of wood chips mainly composed by poplar coming from a local supply chain, where the average wet content is about $47.5 \%$. The composition of this mixture is crucial to ensure an adequate Lower Heating Value of the biomass fuel to reach the expected temperature in the furnace and consequently to 
reduce pollutants emission. For this reason, the biomass acquired by the local supply chain from different sources is subjected to a daily check capable, for example, to measure the average moisture content in the wood and consequently to identify the best composition of the mixture.

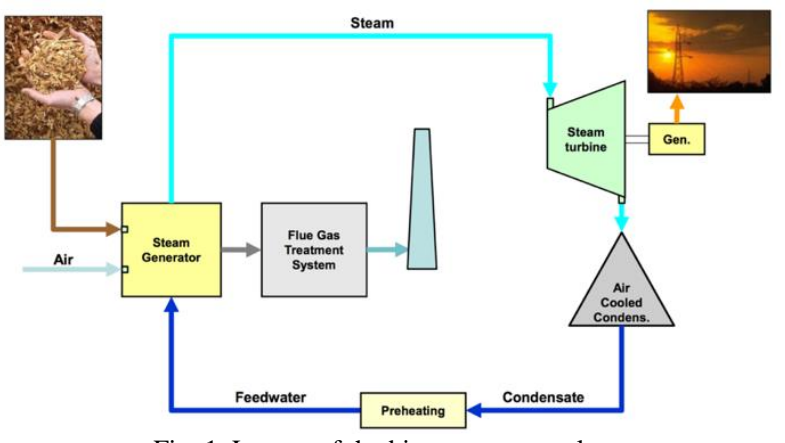

Fig. 1. Layout of the biomass power plant.

A storage capacity of about 7 days in form of trunk trees was also planned to ensure continuity in energy generation during seasonal variation of poplar availability. So, a wood chipper is also installed to convert trunk in wood chips.

The wood chip used for supplying the plant undergoes a mechanical treatment and a successive electromagnetic operation to eliminate ferrous impurities before entering in the furnace. Both treatments allow to improve the performance of the furnace's combustion and consequently to increase the energy generation. The chips combustion at approximatively $950^{\circ} \mathrm{C}$ produces heat for the generation of steam which supplies a turbine coupled to a Medium Voltage (MV) synchronous generator.

Table I shows the main indicators of energy performance obtained by the power plant during its four years' commercial operation. The yearly electricity production of the plant increased of $25 \%$ passing from around $114 \mathrm{GWh}$ in 2013 to around 140-142GWh in 2015 and 2016. On the contrary, the corresponding demand of wood chips slightly decreased from $242 \mathrm{kt}$ in 2013 to $237 \mathrm{kt}$ in 2016. Therefore, the energy efficiency of the whole system significantly increased from $17 \%$ of 2013 to $25 \%$ of 2016 . These results highlight as the first two years were needed to set up the plant operation and to define the suitable mixture of woody biomass capable to ensure higher production and overall efficiency. Consequently, the present number of operating hour is close to 8350 reflecting a quasi-constant plant operation for the whole year.

\begin{tabular}{cccc}
\multicolumn{2}{c}{ TABLE I: ENERGY PERFORMANCES OF BIOMASS POWER PLANT } \\
\hline & $\begin{array}{c}\text { Electricity } \\
\text { Production } \\
(\text { MWh })\end{array}$ & $\begin{array}{c}\text { Biomass } \\
\text { Consumption } \\
(\mathrm{t})\end{array}$ & $\begin{array}{c}\text { Overall } \\
\text { Efficiency } \\
(\%)\end{array}$ \\
\hline $\mathbf{2 0 1 3}$ & 114238.1 & 242993.0 & 17.0 \\
$\mathbf{2 0 1 4}$ & 127174.7 & 246547.6 & 20.6 \\
$\mathbf{2 0 1 5}$ & 140679.3 & 237548.0 & 22.5 \\
$\mathbf{2 0 1 6}$ & 142616.2 & 237569.8 & 25.1
\end{tabular}

The exhaust gases produced during the combustion are then treated in different subsequently steps capable to reduce the pollutants emission under the limits imposed by the national and local authorities.

In particular, the emission levels required for this power plant are significantly lower than the required national limits and the emission of the Best Available Technology (BAT) in
Europe. Table II shows the comparison between the emission limits of the plant and the calculated daily average emission for different pollutants. It is noticeable that, for the measured pollutants at the stack in 2016, the corresponding emission level are lower than the required limits. This condition reflects the relevant capacity of the plant to reduce the pollutant emissions and to ensure a sustainable energy production.

TABLE II: EMISSION PERFORMANCES OF BIOMASS POWER PLANT @ 11\% $\mathrm{O}_{2}$ $\underset{\left(\mathrm{mg} / \mathrm{m}^{3}\right)}{\mathrm{PM}} \underset{\left(\mathrm{mg} / \mathrm{m}^{3}\right)}{\mathrm{HCI}} \underset{\left(\mathrm{mg} / \mathrm{m}^{3}\right)}{\mathrm{NO}_{(}} \underset{\left(\mathrm{mg} / \mathrm{m}^{3}\right)}{\mathrm{SO}_{\mathrm{x}}}$

\begin{tabular}{lcccc}
\hline Legislative Decree 152/06 & 33 & 30 & 267 & 133 \\
Deliberation n.VII/6501 All.C & 50 & n.a. & 450 & 1700 \\
Reference EC BAT & $3-13$ & 25 & $113-167$ & $<33$ \\
Authorized emission levels & 5 & 10 & 80 & 10 \\
Average measured emission levels & $\mathbf{0 . 0 6}$ & $\mathbf{0 . 1 1}$ & $\mathbf{3 0 . 7}$ & $\mathbf{0 . 0 6}$
\end{tabular}

\section{B. Local Area Benefits}

The power station has involved infrastructural construction/expansion in the local area which contributes to increase and to create benefits for the people living in its proximity. The benefits for the Olevano community and the artisan/industrial area were planned according to the Olevano Municipality and they can be briefly summarized, as follows:

- extension and strengthening of the natural gas network

- development of the electricity transmission and distribution network

- extension of the potable water supply system

- extension of the sewerage network

- environment monitoring station

- extension of the provincial road connecting Olevano with Lomellina and State Highway 494 to enable safer and more reliable access to the town.

Moreover, the plant needs of local employer to ensure operation in reliable and safety way. Therefore, positive impact for the local economy and the job market was also registered. In particular, from the job market point of view:

- the construction phase of the power station involved approximatively 200 workers (at the peak)

- the power station yearly operation and maintenance involves approximatively 40 workers

- the local agricultural supply chain and its correlated activities (third-parties, transporters, etc.) involves approximatively 250 units.

Finally, a significant economic impact can be measured in the local area. In fact, the farmers and landowners involved in the biomass supply chain can benefit of approximatively $3 \mathrm{M} € /$ year, while other job positions involved in the territories can benefits of around $7 \mathrm{M} € /$ year.

\section{THE SHORT SUPPLY CHAIN}

As already and briefly described in Section II.A, the biomass power plant is presently supplied by poplar wood chip. The raw material is selected by the supplier in an area within $70 \mathrm{~km}$ of radius from the position of the power plant. This condition called "short supply chain" allows to obtain Green Certificates (GC) for the net electricity production 
injected into the transmission grid under the incentive scheme introduced by the Italian Government [7]. The corresponding economic benefit of the GCs is evaluated by the Italian Energy Authority (GSE) by multiplying the net electricity production for the economic value of the energy (expressed in $€ / \mathrm{MWh}$ ). This economic value changes yearly and it was fixed at $100.08 € / \mathrm{MWh}$ in 2015 [10]. The biomass plants with short supply chain enjoy an additional benefit since the generated net electricity is multiplied by a factor equal to 1.8 kept constant for 15 years.

In the Italian context, where wood chips are expensive as well as the installation costs of the biomass power plant [11], the impact of the incentive scheme is relevant to ensure the economic sustainability of the investment. Because of this, a preliminary evaluation was performed before the biomass plant installation in order to identify the available potential biomass within the short supply chain area.

The presented biomass power plant can be used as a case study for introducing a GIS analysis capable to evaluate the biomass availability in a given area. This area is defined considering the biomass power plant location in the centre of a circumference with $70 \mathrm{~km}$ of radius according to the short supply chain definition in [7]. According to the above hypothesis, four different Italian Regions were involved in the evaluation. In the next Sections the GIS analysis will identify the potential poplar biomass available according to a sustainable and short supply chain.

\section{A. GIS Analysis}

The analysis requires a set of georeferenced data to develop the model used to calculate the amount of biomass that can be used for energy goals. The biomass, that can be extracted from a specific area, depends on many different geomorphologic factors as well as biological growth factors, type of forest management and other possible administrative restrictions. Therefore, the first phase of the work is the implementation of a Territorial Informative System that include the following themes:

- administrative boundaries;

- digital elevation model (DEM);

- main and forest roads;

- forest inventory containing these information: forest typologies, method of woodland

- management (coppice or high forest), Periodic Annual Increment indexes, Biomass Expansion

- Factors, Wood Basic Density values.

The dataset comes from different public data sources [12]-[15]. The analysis is based on raster and vector data with a large scale of 1:10.000 and a resolution of $10 \mathrm{~m}$ per squared pixel, and it has been performed by free and open source software. In particular, the study was carried out using these solutions:

- ARCMAP as ARCGIS 10.3 tool developed by ESRI [16] for vector processing, geodatabase, map display and processing data

The data recovered from the different sources are collected into a dedicated geodatabase, because this solution can quickly process large amounts of data, optimizing calculation time. The information included in the national or regional inventory are recovered in vector format, so an area is divided into polygons. The information associated to vector format have been assembled together and processed.

\section{B. Estimating Harvesting Sustainable Biomass}

The analysis is performed to obtain information on how much poplar biomass can be harvested. The total amount is defined as the sum of poplar from forest biomass and from arboriculture. After that, the amount of biomass used for energy purpose can be evaluated according to sustainable ecological principles.

The forest biomass availability may be defined as a function of the periodic annual increment of poplar, as this value refers to the stock of natural capital and a sustainable yield [5]. Sustainable wood energy extraction is defined as the maximum rate of woodchips obtainable from poplar that is equal to its annual increment. The value of periodic annual increment used for the area is based on [17].

Thus, annual biomass availability can be estimated by using the relationship between forest typology and periodic annual increment. In general, different forest typologies have different forestry management, leading to variations of annual increment. For poplar, the management considered is the coppice. The annual biomass availability in each $\mathrm{j}$-th polygon can be calculated as the product between the $\mathrm{j}$-th polygon area and the periodic annual increment of poplar, according to [18]:

$$
B_{a_{j}}=S_{j} \cdot I_{C} \cdot(1 \pm 2 E S \%)
$$

where $\boldsymbol{S}_{\boldsymbol{j}}$ is the polygon area and $\boldsymbol{I}_{\boldsymbol{C}}(\mathbf{1} \pm \mathbf{2 E S} \%)$ is the periodic annual increment plus or minus standard error (ES). The sum of annual biomass availability for each typology and each polygon gives the overall annual biomass availability for a specific area.

However, the periodic annual increment represents only the growth rate of the trunk, but the top and the branches of a tree also grows in. Thus, an additional factor must be introduced in the eq. (1) to evaluate the overall aboveground available biomass by using the formula proposed in [18] where the Biomass Expansion Factor (BEF) is introduced, as follows:

$$
B_{a}=\sum_{j} S_{j} \cdot I_{C} \cdot(1 \pm 2 E S \%) \cdot B E F
$$

All the above-mentioned equations define the amount of available biomass which can be harvested from a given area, in terms of cubic meter of fresh wood. However, the calculated biomass includes moisture. This water content of fresh biomass can be evaluated, but it depends on many factors. As a first approximation, the only factor considered in this work is related to the forest typology (i.e., different forest typologies have different moisture content). Hence, a conversion factor was used to convert fresh volume into dry weight. In particular, the Wood Basic Density (WBD) conversion factor (expressed in terms of $t / \mathrm{m} 3$ ) was used, according to the values proposed in [19].

The conversion factor permits to remove the water content in the available biomass, thus all the calculated quantities are represented in terms of dry tons instead of fresh volume. As a result, the energy content of the wood is not function of the 
water content. The introduction of the Wood Basic Density conversion factor modifies the equation 2, as follows:

$$
B_{a}=\sum_{j} S_{j} \cdot I_{C} \cdot(1 \pm 2 E S \%) \cdot B E F \cdot W B D
$$

Equations from (1) to (3) define the theoretical potential biomass that can be obtained in a given area. However, some limitations related to the site characteristics that can limit the forestry operations and the forest machinery usage have to be introduced.

Firstly, a limitation factor, terrain suitability (TS), on the annual potential biomass that can be harvested needs to be introduced. That factor is related to the geomorphological characteristics of the terrain altitude and slope gradient (see Table III), not allowing or limiting the mechanization of operations [18].

Another limitation factor is the distance between forest and road and is called road distance (RD). Forests that are located at a distance more than $2500 \mathrm{~m}$ from the roads have costs so high which nullify the productivity, independently from the site slope [18]. For this reason, another reduction factor called proximity factor is added. The proximity factor assumes value 0 or 1 for distances greater or lesser than 2500 $\mathrm{m}$ respectively.

TABLE III: CLASSIFICATION THRESHOLDS FOR SITE SUITABILITY FOR

\begin{tabular}{lcccc}
\multicolumn{4}{c}{ FOREST RESIDUE REMOVAL } \\
\hline & $\begin{array}{c}\text { Highly } \\
\text { suitable }\end{array}$ & $\begin{array}{c}\text { Moderately } \\
\text { suitable }\end{array}$ & $\begin{array}{c}\text { Marginally } \\
\text { suitable }\end{array}$ & Unsuitable \\
\hline Reduction & 0.75 & 0.5 & 0.25 & 0 \\
Factor & $<5^{\circ}$ & $5^{\circ}-10^{\circ}$ & $10^{\circ}-25^{\circ}$ & $>25^{\circ}$ \\
Slope & $<1500 \mathrm{~m}$ & $<1500 \mathrm{~m}$ & $<1500 \mathrm{~m}$ & $>1500 \mathrm{~m}$
\end{tabular}

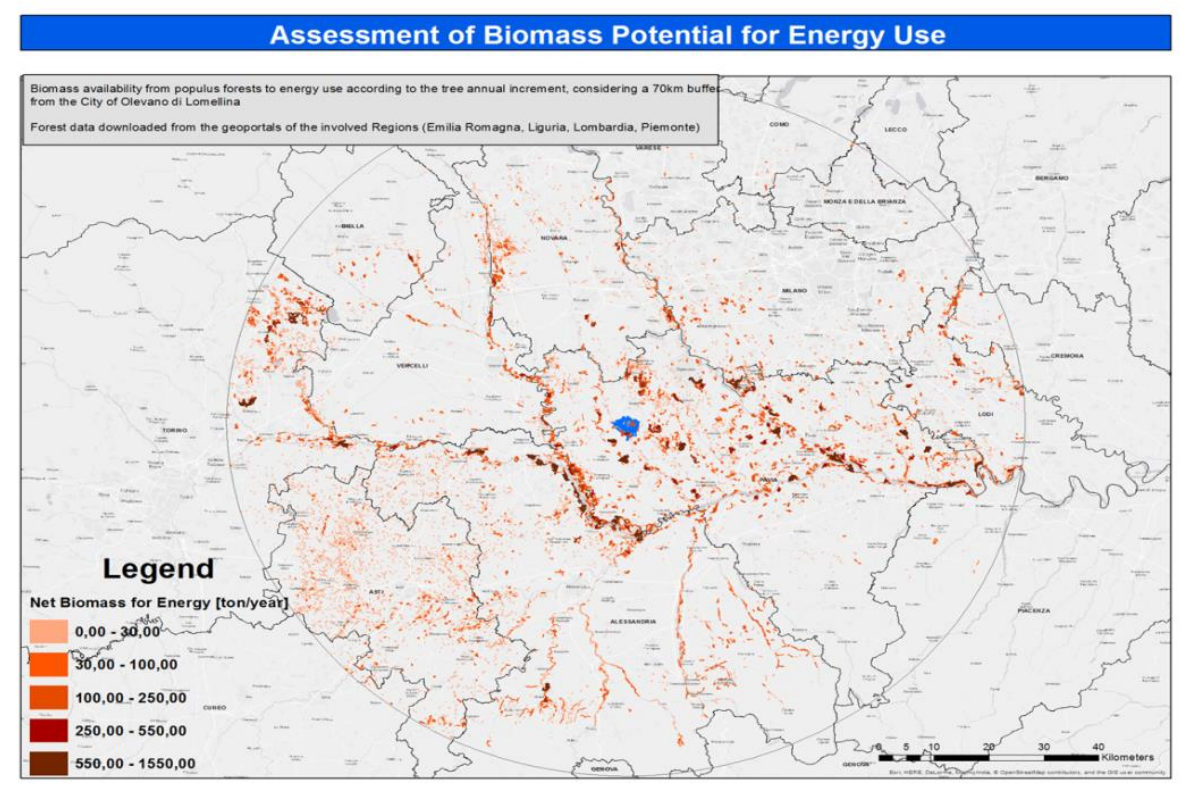

Fig. 2. Map of the biomass availability.

Similarly, the arboriculture biomass availability was also calculated and summed to the forest biomass. In particular, the arboriculture biomass was defined in the GIS analysis by using only equation 3 and thus neglecting the reduction factors used for the forest biomass.

\section{CAse Study Results}

The GIS analysis described in Section III.A and III.B was then applied considering the biomass power plant location in the center of a circumference with $70 \mathrm{~km}$ of radius (i.e. the biomass power plant is located on the blue area of Fig. 2). Fig. 2 shows the spatial distribution of the poplar wood within the area analyzed which involves 4 Italian Regions (i.e. mainly Piedmont and Lombardy, marginally Liguria and Emilia-Romagna) where the overall surface of poplar availability is around 38200 ha.

The analysis underlines that the maximum volume of potentially available poplar biomass is approximatively equal to $458126 \mathrm{~m} 3 /$ year, which corresponds to around 240 $\mathrm{kt} / \mathrm{year}$ of dry biomass. These values are calculated according to a sustainability approach where the biomass availability is related to the periodic annual increment of poplar trees.
The result highlights how the present poplar availability should be potentially exploited to supply the biomass power plant of the case study within the short supply chain definition to obtain economic incentives. In fact, Table I evidences that the poplar wood chips needed is approximatively equal to $237 \mathrm{kt} /$ year referred to the actual weight, while the calculated availability is referred to the dry weight.

The technology capacity of the power plant together with an available short supply chain demonstrates as the biomass plant can be efficiently realized in Italian context from the energy and economical point of view ensuring also lower pollutant emissions. In particular, another plant with similar capacity could be potentially installed in the same area, if all the available biomass was used for energy purpose.

\section{ELECTROMAGNETIC SUSTAINABILITY}

The supply overhead line with a rated voltage of $132 \mathrm{kV}$ and a rated current of $750 \mathrm{~A}$ at $50 \mathrm{~Hz}$ can be considered as the most important external electric and magnetic field sources. It is worth noting that the above line rated current is much higher than the actual service current $(<100 \mathrm{~A})$ and the 
actual magnetic fields are strongly lower than the ones predicted according to the line rated characteristics. Anyway, the worst case was verified on the design phase and levels lower than the limits were predicted. The installed six conductor lattice towers follow the Italian transmission Standards with the conductor closer to the ground at a rated height of $24 \mathrm{~m}$ give rise to levels of the computed electric and magnetic field lower than the law limits. It is recalled that the people exposition limits in Italy are:

- Electric field: $5000 \mathrm{~V} / \mathrm{m}$

- Magnetic field: $100 \mu \mathrm{T}$ according European suggestion and $3 \mu \mathrm{T}$ for a daily exposition longer than $4 \mathrm{~h}$ in case of new installations on the basis of an Italian Law.

As far as the work place characteristics, the worker exposition limits in the design phase were:

- Electric field: $10000 \mathrm{~V} / \mathrm{m}$,

- Magnetic field: $400 \mu \mathrm{T}$

And ICNIRP organization in 2010 increased the exposition limit of magnetic field to $1000 \mu \mathrm{T}$ so the design phase satisfied with a large margin the new requests.

\section{CONCLUSION}

This paper present the operational results of an existing biomass power plant located in the northern part of Italy. The results highlight the relevance of a short supply chain capable to supply poplar wood chips for the plant ensuring economic and environmental sustainability. In fact, the plant has lower pollutant emissions compared to the national and local limits thanks to the wood chips characteristics, plant technologies and to the definition of a better mixture of biomass.

The economical sustainability is then ensured by the incentive scheme which supports the investment and operational costs. However, the Italian incentive scheme is based on a short supply chain for the wood chips. For this reason, other new plant should be designed according to a presented approach based on GIS analysis capable to evaluate the biomass availability in the area within the short supply chain. The GIS analysis was performed by considering the existing plant as a practical case study. The results confirm the yearly availability of the poplar woody biomass in the area for the existing plant. Moreover, the same availability is capable to ensure the installation of a similar power plant if all the available biomass was used for energy purpose.

\section{REFERENCES}

[1] European Environmental Agency (EEA), “Annual European Union greenhouse gas inventory 1990 - 2011 and inventory report 2013. Technical report No 8/2013," 2013.

[2] Intergovernmental Panel on Climate Change (IPCC), "Renewable energy sources and climate change mitigation - Summary for policymakers and technical summary. Special report on renewable energy sources and climate change mitigation," 2011.

[3] "Directive 2012/27/EU of the European parliament and of the council of 25 October 2012. Energy efficiency, amending directives 2009/125/EC and 2010/30/EU and repealing directives 2004/8/EC and 2006/32/EC".

[4] "Directive 2009/28/EC OF the European parliament and of the council of 23 April 2009. The promotion of the use of energy from renewable sources and amending and subsequently repealing Directives 2001/77/EC and 2003/30/EC"

[5] M. Teobaldelli, Z. Somogyi, M. Migliavacca, and V. A. Usoltsev, "Generalized function of biomass expansion factors for conifers and broadleaved by stand age, growing stock and site index," Forest Ecology and Management, vol. 257, no. 3, pp. 1004-1013, 2009.

[6] Z. Pietro, L. Chiara, S. Raffaele, T. Clara, V. Alfonso, P. Zatelli, and M. Ciolli, "A GIS decision support system for regional forest management to assess biomass availability for renewable energy production," Environment Modelling \& Software, vol. 38, pp. 203-213, 2012.

[7] Decreto ministero dello sviluppo economico 23 Giugno 2016. Incentivazione dell'energia elettrica prodotta da fonti rinnovabili diverse dal fotovoltaico.

[8] K. Vavrova, J. Knapek, J. Weger, T. Kralik, and J. Beranovsky, "Model for evaluation of locally available biomass competitiveness for decentralized space heating in villages and small towns," Renewable Energy, 2017.

[9] M. Uris, J. I. Linares, and E. Arenas, "Feasibility assessment of an Organic Rankine Cycle (ORC) cogeneration plant (CHP/CCHP) fueled by biomass for a district network in mainland Spain," Energy, vol. 133, pp. 969-985, 2017.

[10] Gestore Servizi Energetici (GSE). (2015). Price of green certificates. [Online]. Available: http://www.gse.it/it/salastampa/news/Pages/Certificati-Verdi-prezzodi-ritiro-dei-certificati-relativi-alla-produzione-2015-.aspx

[11] International Renewable Energy Agency (IRENA), "Renewable Power Generation Costs in 2014," 2015.

[12] Piedmont Regional Forest Information System (SIFOR). [Online]. Available:

http://www.sistemapiemonte.it/cms/privati/territorio/servizi/526-siste ma-informativo-forestale-regionale.

[13] Forestry types of the Liguria Region. [Online]. Available: https://www.regione.liguria.it/in-regione/opendata/item/7175-tipi-for estali-della-regione-liguria-sc-125000-ed-2013.html

[14] Geoportal catalogue of lombardy region. [Online]. Available: http://www.geoportale.regione.lombardia.it/

[15] Geoportal catalogue of emilia-romagna region. [Online]. Available: geoportale.regione.emilia-romagna.it

[16] ArcGIS software. [Online]. Available: http://www.esri.com/arcgis/about-arcgis

[17] G. Tabacchi, F. De Natale, L. Di Cosmo, A. Floris, C. Gagliano, P. Gasparini, L. Genchi, G. Scrinzi, and V. Tosi, “L'Inventario Nazionale delle Foreste e dei serbatoi forestali di Carbonio," MiPAF - Corpo Forestale dello Stato - Ispettorato Generale, CRA - ISAFA, 2007.

[18] A. Barbati, P. Corona, M. V. Chiriaco, and L. Portoghesi, "Indici di produttivita' boschiva, rilievo indici di relazione tra produzioni forestali e biomassa residuale associata, analisi del mercato della biomassa forestale in Italia," Report RSE/2009/51, 2009.

[19] Regione Emilia-Romagna Assessorato Agrigoltura, Disciplinari di Produzione Integrata del Pioppo. Norme Techinche Fase di Coltivazione.

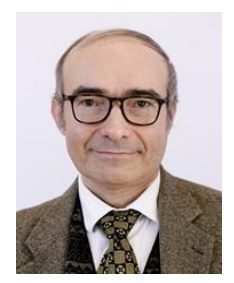

Alberto Cavallo graduated in electrical engineering at Politecnico di Torino in 1985, started his activity in fiat engineering of Turin in the field of electrical systems engineering, moving then to control systems for power plants and general utilities for factories and large civil projects. He was involved in several projects including cogeneration plants for paper mills, utilities for car factories, Lingotto exhibition center, the district heating system of Torino Sud and several combined cycle power plants in Italy and Brazil. As Fiat Engineering was merged into Maire Tecnimont Group he became Head of the Electrical Department and then Head of the Electrical and Instrumentation cluster of Tecnimont, the main EPC company of the Group, operating in petrochemical, fertilizers, oil\&gas and power plants areas. Tecnimont designed and built the Biolevano biomass power plant.

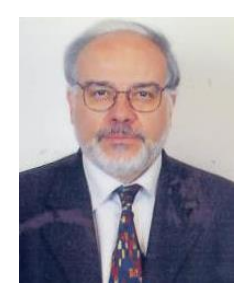

Bruno Covili Faggioli graduated in mechanical and nuclear engineering, started his activity on 1970 in Ansaldo group in the field of nuclear power plant (Caorso 600 MW-Italy and Creys Malville-Super Phoenix $1200 \mathrm{MW}$ - France). He spent all his career in the design, construction and operation of power plants of several size and type: nuclear, conventional plants feed with oil and/or coal, cogeneration plant, geothermal plant, combined cycle, IGCC and finally 
waste to energy and biomass power plant. He is now the CEO of the company owner of Biolevano biomass power plant.

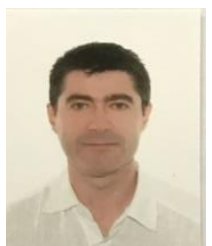

Paolo Guizzetti graduated in electronic engineering at Politecnico di Milano in 1992, started his activity in ABB group in the field of power plant control system engineering, and moving to power plant process and control optimization and troubleshooting. He was involved in several power plant projects including conventional fossil fuel units, combined cycles, cogeneration plant, waste to energy and biomass plant, in both green filed and retrofit application overcoming the $3000 \mathrm{MW}$ of installed gross power implemented projects. Since 2012 is acting as Power and Utility Technology Manager in Tecnimont which is the EPC company of the MaireTecnimont Group, operating in petrochemical, fertilizers, oil\&gas and power plants areas. He was directly involved in troubleshooting and plant optimization for the Biolevano biomass power plant.

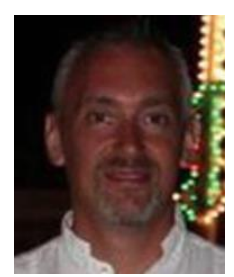

Paolo Lazzeroni is a Ph.D in electrical engineering. He completed his Ph.D in 2011 at Electrical Engineering Department of Politecnico di Torino related to modeling and simulation of complex poligeneration system. He is a senior researcher in the energy \& security area at the research center Istituto Superiore sui Sistemi Territoriali per l'Innovazione in Torino. His main research activities are related to the impact of RES distributed generation on the electric grid, modeling and optimal management of complex energy systems, exploitation of RES generation.

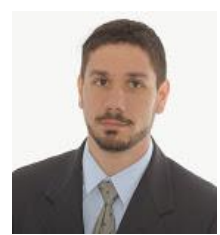

Francesco Moretti has a graduate in Geology. He completed his study in 2014 at the Geology-Geochemistry and Minerology Department of "Università La Sapienza" in Rome. The main topic of his thesis was related to the geological mapping of the volcanic terrains in the northern part of the Lazio Region. He has also a postgraduate degree in spatial planning at the Civil Engineering Department of "Università di Roma Tor Vergata" in 2016. Currently he is a researcher in the Energy \& Security area at the research center Istituto Superiore sui Sistemi Territoriali per l'Innovazione in Torino. His main activities are related to the development of Geospatial databases and GIS mapping.

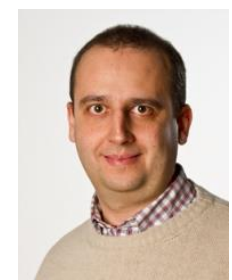

Federico Stirano is an electronic engineer. His main expertise includes distributed generation from renewable sources, smart grids and virtual power plants. He is a senior researcher responsible for the main energy related projects in the energy \& security area at the research center istituto superiore sui Sistemi Territoriali per l'Innovazione in Torino, with specific focus on the simulation and analysis of the impact of renewable production and storage devices on the grid at national and transnational level. He is also involved in project for the management of database for GIS application.

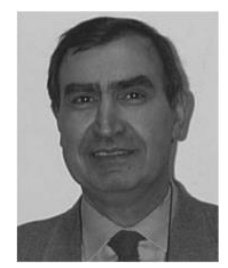

Michele Tartaglia eceived the laurea degree in electrical engineering from the Politecnico di Torino, Turin, Italy, in 1971.

In 1973, he joined the Istituto Elettrotecnico Nazionale "Galileo Ferraris," Turin, where he carried out theoretical and experimental studies on breaking apparatus and computation of electromagnetic fields in nonlinear devices. From 1982 to 2010, he was an associate professor, and is currently a full professor with the Politecnico di Torino. He is also the scientific responsible of research contracts with public institutions and private companies, and is involved in European community projects. He has authored more than 110 scientific papers. His main research interests include the study of breaking apparatus, electromagnetic fields by means of analytical and numerical methods, mitigation of low-frequency magnetic fields, security in electrical power systems, and rational use of energy. 